\title{
O DIMINUTIVO NA DEFINICIÓN ACTUAL DO ESTÁNDAR MORFOLÓXICO
}

\author{
Larisa Santos Suárez
}

Imaxin Software

O tema que imos desenvolver nesta exposición enmárcase dentro do traballo realizado entre marzo de 2002 e outubro de 2003 na área de tecnoloxía lingüística da empresa Imaxin Software. Este traballo é froito das tarefas de investigación e de análise dos datos recompilados sobre a lingua galega (Álvarez 2002 e Álvarez/Xove 2002) realizadas dentro do proxecto de I+D Universidade-Empresa "Desenvolvemento de ferramentas informáticas de revisión lingüística para a lingua galega". O proxecto foi desenvolvido conxuntamente por un equipo de traballadores de Imaxin Software e varios membros do Seminario de Lingüística Informática (SLI) da Universidade de Vigo ${ }^{1}$.

\section{OBXeCTIVOS DO PROXECTO}

O primeiro obxectivo deste proxecto era desenvolvermos, con axuda da informática, un dicionario de palabras da lingua galega o máis amplo e organizado posible, de maneira que calquera ferramenta de revisión lingüística desenvolvida a posteriori puidese tomar como base un lexicón razoablemente amplo e exhaustivo. Partindo da información que conteñen os habituais dicionarios de lemas ou "palabras base" (Álvarez/Xove 2002: 224), o que buscabamos era crear unha ferramenta informática que xerase automaticamente unha serie de flexións para cada un deses lemas, tendo en conta cada categoría gramatical e o tipo de morfemas afixais (flexionais e / ou derivativos) que lle son máis propios, de maneira que nos fose posible recoñe-

1. O proxecto foi subvencionado pola Secretaría Xeral de Investigación e Desenvolvemento da Xunta de Galicia, dentro do programa de investigación 2001-2004 (ref. PGIDT01TICC06E). Foi dirixido por Jose Ramom Pichel Campos (xefe da área de tecnoloxía lingüística de Imaxin Software) e o Prof. Xavier Gómez Guinovart (Director do SLI) e nel participaron José Luis Aguirre Moreno (SLI), Alberto Álvarez Lugrís (SLI), Antonio Fernández Cabezas (Imaxin Software), Elena Sacau Fontenla (SLI) e Larisa Santos Suárez (SLI e Imaxin Software). 
cer un amplo abano de "palabras de discurso" (Álvarez/Xove 2002: 224). Así por exemplo, a categoría "verbo", que nun dicionario normal de lemas se manifesta tan só mediante as formas de infinitivo (consideradas como "palabras base"), consiste nun amplo conxunto de formas xeradas por combinación do tema con todos os morfemas flexivos correspondentes ás categorías de modo, tempo, persoa e número, que conforman o paradigma conxugacional de cada verbo. O substantivo, unha das categorías que imos tratar con máis profundidade nesta exposición, tamén aparece representado nos habituais dicionarios de lemas pola súa forma masculina singular (salvo nos casos en que o xénero é explicitamente feminino ou o número plural), se ben existe un amplo abano de morfemas facultativos que se lle poden engadir e cos que se pode xerar todo un paradigma de formas nominais.

Unha boa ferramenta informática de revisión lingüística en calquera lingua debería ser capaz de recoñecer o maior número posible destas combinacións "lema (entendido aquí como "radical" ou "raíz") + afixos". De feito, moitas destas formas derivadas teñen de por si entrada propia nos dicionarios (p. ex.: libro - libraría, libreiro...), posto que son recoñecidas polos falantes como palabras independentes con entidade propia. En realidade, son palabras novas creadas a partir doutras. No entanto, queda sen recompilar toda outra serie de formas (diminutivos e aumentativos no substantivo, comparativos e superlativos no adxectivo, entre outras) que non posúen esta etiqueta de "palabras independentes", senón que son concibidas polos falantes como "variantes" ou "subprodutos" da palabra da que derivan. En realidade, ao engadirmos un morfema diminutivo ou aumentativo á raíz dun substantivo ou dun adxectivo estamos determinando o significado léxico da palabra, pero non creando unha nova. Por iso este tipo de formacións nunca se recollen nos dicionarios, a pesar da súa alta frecuencia de uso. Foi precisamente esta alta frecuencia de uso a que nos fixo pensar que sería interesante, mesmo imprescindible, tentar dar cabida no noso dicionario de palabras ao maior número posible delas, de maneira que puidesen ser facilmente identificables por calquera ferramenta de revisión lingüística informatizada.

Partindo desta base teórica, e utilizando un dicionario en formato electrónico como fonte de datos, centramos os nosos esforzos iniciais en deseñar uns modelos de flexión específicos para cada categoría de palabra que, a partir do lema correspondente, xerasen automaticamente as formas flexivas que consideramos máis importantes para cada unha delas. Lamentablemente, o noso traballo non pode recoller todas as posibilidades de flexión que poden existir, sobre todo para categorías tan abertas á flexión coma o substantivo e o adxectivo, das que se pode derivar multitude de formas. De maneira que tentamos seleccionar as que nos pareceron máis interesantes e produtivas. 


\section{O MORFEMA DIMINUTIVO}

Ímonos centrar, pois, nun dos morfemas que máis xogo dá na modificación de palabras na nosa lingua, o diminutivo, polo que nos pareceu imprescindible incluílo na nosa definición de modelos de flexión para as dúas categorías de palabras coas que se adoita asociar: o substantivo e o adxecti$\mathrm{vo}^{2}$. O diminutivo, concretamente o morfo $\mid$ iñ $\mid$, é con diferenza o morfema modificador máis habitual no substantivo e no adxectivo, nun principio utilizado como determinante do "tamaño ou magnitude do expresado polo substantivo [ou adxectivo]" (Álvarez/Xove 2002: 406), pero na realidade con valores ou funcións que chegan moito máis aló (usos afectivos que intensifican o significado da base ou engaden un valor de emotividade e que, en consecuencia, aumentan a súa frecuencia de uso). É tamén o modificador máis facilmente aceptado por un maior número de substantivos e adxectivos, o que permite a súa combinación con practicamente calquera unidade léxica destas dúas categorías de palabras. Non obstante, a pesar da súa frecuencia de uso, á hora de crear uns modelos de flexión xenéricos para catalogar os substantivos e adxectivos, atopámonos co problema da escasa definición que as regras prescritivas da lingua galega conteñen sobre a formación do diminutivo. A vacilación -iñ-/-ciñ- non está sempre clara nin suficientemente documentada, de maneira que conviven en moitos casos distintas variedades rexionais sen que a norma se decante por unha ou outra (Álvarez 2002).

A continuación imos expoñer quince grupos de palabras que exemplifican os modelos de flexión que puidemos crear tendo en conta toda esta variación. Partimos da terminación do lema para estipular o alomorfo que se lle debe engadir a cada tipo de terminación, e analizamos as dificultades, dúbidas ou variacións atopadas neste proceso.

\subsection{A formación do diminutivo: problemas detectados na definición do estándar}

2.1.1. O primeiro grupo é o máis amplo e representativo. Recolle todos os substantivos e adxectivos rematados en vogal átona precedida de consoante, que forman o diminutivo eliminando esa vogal e engadindo o morfo |iñ | máis os correspondentes morfemas de xénero e número (Álvarez/Xove

2. O diminutivo é un morfema tan usual e frecuente na lingua galega, que se pode mesmo aplicar a categorías como o adverbio ou o verbo, se ben as dúas clases de palabras coas que máis habitualmente se identifica son o substantivo e o adxectivo. Por iso nos cinguiremos simplemente a estas dúas na nosa exposición. 
2002: 407). Aos efectos dunha revisión lingüística informatizada, o único que cómpre notar é o cambio de sílaba tónica e que as consoantes /c/, /g/ e /z/ que preceden a vogal final de palabra cambian a /qu/, /gu/ e /c/ ao se antepoñeren á vogal /i/ do morfema diminutivo.

\begin{tabular}{|c|c|c|c|}
\hline \multirow{3}{*}{$\begin{array}{l}\text { TERMINACIÓN LEMA } \\
\text { - vogal átona }\end{array}$} & \multirow{3}{*}{$\begin{array}{l}\text { TERMINACIÓN DIMINUTIVO } \\
\text {-iñ- }\end{array}$} & \multicolumn{2}{|r|}{ EXEMPLOS } \\
\hline & & SUBST. & 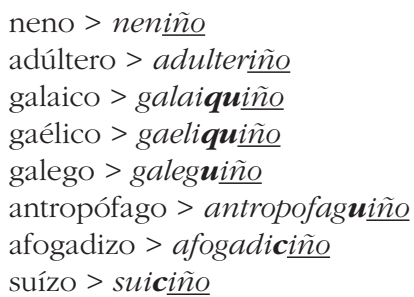 \\
\hline & & ADX. & $\begin{array}{l}\text { alto }>\text { altiño } \\
\text { acéfalo }>\text { acefaliño } \\
\text { adunco }>\text { adunquiño } \\
\text { abiótico }>\text { abiotiquiño } \\
\text { abadengo }>\text { abadenguiño } \\
\text { análogo }>\text { analoguiño } \\
\text { achadizo }>\text { achadiciño } \\
\text { suízo }>\text { suiciño }\end{array}$ \\
\hline
\end{tabular}

2.1.2. O segundo grupo recolle os substantivos e adxectivos rematados en vogal átona precedida de vogal tónica coa que forma hiato. Nestes casos cae a vogal átona final, o mesmo que no caso anterior, e engádese o morfo | iñ |, coa única particularidade de que o /i/ debe levar til para marcar o hiato (Álvarez/Xove 2002: 407).

TERMINACIÓN LEMA
- vogal átona
precedida de
vogal tónica
(hiato)

\author{
EXEMPLOS \\ SUBST. galileo > galileîno \\ galináceo $>$ galinaceîno \\ río $>$ riiño \\ radiografía $>$ radiografiiña \\ ADX. alleo > alle $\underline{i n ̃ o}$ \\ asiduo $>$ asiduiño \\ aéreo $>$ aereiño \\ baldío > baldi $\underline{i n o}$
}

2.1.3. O terceiro grupo inclúe todos os substantivos e adxectivos rematados en vogal átona precedida de /i/ co que forma ditongo crecente. Novamente a formación do diminutivo esixe a perda desa vogal átona final. Ao engadirmos o morfo $\mid$ iñ $\mid$, os dous /i/ do lema e mais do morfema diminutivo quedan reducidos a un só (Álvarez/Xove 2002: 407). 


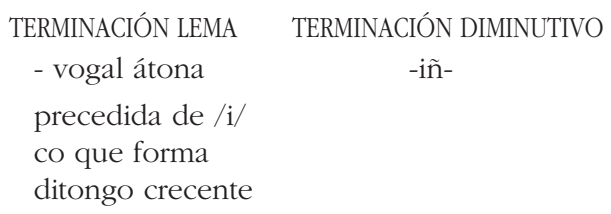

\author{
EXEMPLOS \\ SUBST. cambio > cambiño \\ ADX. acadio $>$ acadiño
}

2.1.4. O cuarto grupo presenta maior dificultade, xa que entra nun ámbito menos definido na lingua estándar. Inclúe os substantivos e adxectivos rematados en vogal tónica e se ben semella que "-iñ- é de uso maioritario e aceptable en tódolos casos, existe unha variante diatópica -ciñ-, que continúa xeograficamente a forma portuguesa, con certa presencia nas gramáticas descritivas do galego estándar" (Álvarez 2002: 99). Non está claro que palabras exactamente admiten ou non o morfo $\mid$ ciñ $\mid$, pero parece evidente que "en áreas occidentais hai tendencia a introduci-la variante $\mid$ ciñ $\mid$ do diminutivo en tódalas palabras rematadas en vocal tónica: pé > peciño, mamá > mamaciña, etc." (Álvarez/Xove 2002: 408). De aí que nós incluamos as dúas posibilidades nos nosos modelos de flexión para a revisión lingüística.

\begin{tabular}{|c|c|c|c|}
\hline \multirow{2}{*}{$\begin{array}{l}\text { TERMINACIÓN LEMA } \\
\text { - vogal tónica }\end{array}$} & TERMINACIÓN DIMINUTIVO & & EXEMPLOS \\
\hline & $\begin{array}{l}\text {-iñ- } \\
\text {-ciñ- }\end{array}$ & SUBST. & $\begin{array}{l}\text { chimpancé > chimpanceiño / } \\
\text { chimpanceciño } \\
\text { pé }>\text { peíno / peciño } \\
\text { mamá > mamaiña / mamaciña }\end{array}$ \\
\hline & & ADX. & israelí > israeliñno / israeliciño \\
\hline
\end{tabular}

2.1.5. O quinto grupo recolle os substantivos e adxectivos rematados en ditongo decrecente (-eu, -ou, $-a u,-a i,-e i,-o i)$, para os que se documentan os dous alomorfos habituais do diminutivo $\mid$ iñ $\mid$ e $\mid$ ciñ $\mid$. A distribución dun e doutro semella basearse en criterios de distribución xeográfica e cronolóxicos, que establecen a forma $\mid$ ciñ $\mid$ como preferente no sur e no oeste de Galicia e entre as xeracións máis novas e a forma $\mid$ iñ $\mid$ no resto do país e entre as xeracións máis vellas (Álvarez 2002: 100). Á vista destes datos, as nosas ferramentas de revisión lingüística ofrécenlle ao usuario ambas as dúas posibilidades.

O problema con este grupo está na redución das secuencias /i’i/ e /u'i/ a /'i/. Mentres que o primeiro caso non presenta maior dificultade, por similitude co comportamento das palabras rematadas en ditongo crecente (cambio > cambiño, rei > reiño), a segunda secuencia resulta máis problemática. Hai datos que avalan a devandita redución co ditongo final /eu/ (xudeu > xudeiño), "quizais amparada na tendencia ó hiato final na lingua espontánea" (Álvarez 2002: 100). No entanto, cos outros dous ditongos en $-u(-a u$ e $-o u)$ a redución non semella ser tan evidente, polo que parecen máis frecuentes formas diminutivas como carlouiño ou tauiño. 


$\begin{array}{cc}\text { TERMINACIÓN LEMA } & \text { TERMINACIÓN DIMINUTIVO } \\ \text { - ditongo } & \text {-iñ- } \\ \text { decrecente } & \text {-ciñ- }\end{array}$

2.1.6. O sexto grupo recolle os substantivos e adxectivos rematados en $-u o /-u a$ ou -üe. Como calquera outro substantivo ou adxectivo rematado en vogal átona ou en ditongo crecente, non existe maior problema á hora de seleccionarmos o alomorfo |iñ $\mid$ para crear a forma diminutiva. O que non resulta tan fácil delimitar é se o / $\mathrm{u} /$ da terminación do lema forma hiato ou ditongo co /i/ do sufixo -iño e, polo tanto, se este /i/ debe levar til ou non. A documentación consultada non aclara nada ao respecto, de maneira que mentres non haxa un pronunciamento normativo parécenos máis lóxico supoñer que, en congruencia co comportamento habitual das vogais ante o /'i $\mathrm{i} /$ tónico do diminutivo, deben formar hiato.

\begin{tabular}{|c|c|c|c|}
\hline TERMINACIÓN LEMA & TERMINACIÓN DIMINUTIVO & & EXEMPLOS \\
\hline$-u o /-u a,-\ddot{u} e$ & -íñ- & SUBST. & $\begin{array}{l}\text { residuo }>\text { residuiñ } \\
\text { quechua }>\text { quechuiñ } \\
\text { lingua }>\text { lingüiñ }\end{array}$ \\
\hline & & ADX. & $\begin{array}{l}\text { continuo }>\text { continuiño } \\
\text { bilingüe }>\text { bilingüiñ }\end{array}$ \\
\hline
\end{tabular}

2.1.7. O sétimo grupo cataloga todos os substantivos e adxectivos rematados en -ble. Esta terminación é con moito máis frecuente en adxectivos ca en substantivos e o habitual é que ao formar o diminutivo o sufixo -ble se modifique en -bil-, "forma máis próxima á orixe latina da que procede" (Álvarez/Xove 2002: 424), dando lugar a pares como amable > amabiliño, agradable $>$ agradabiliño. Non obstante, nalgúns substantivos en -ble tamén semella posible unha formación regular en -bliño, como se mostra no cadro inferior, que nos parece importante ter en conta.

$\begin{array}{cc}\text { TERMINACIÓN LEMA } & \text { TERMINACIÓN DIMINUTIVO } \\ \text {-ble } & \text {-biliñ- }\end{array}$
EXEMPLOS

SUBST.

ADX.

2.1.8. No grupo oito incluímos os substantivos e adxectivos rematados en $-l,-s,-r$ e $-z$. Para formaren o diminutivo, só teñen que engadir o morfo 
| iñ | directamente a continuación do lema, como se ve nos exemplos do cadro seguinte (Álvarez/Xove 2002: 407).

\begin{tabular}{|c|c|c|c|}
\hline TERMINACIÓN LEMA & TERMINACIÓN DIMINUTIVO & & EXEMPLOS \\
\hline \multirow[t]{2}{*}{$-l,-s,-r,-z$} & -iñ- & SUBST. & $\begin{array}{l}\text { animal }>\text { animaliño } \\
\text { deus }>\text { deusiño } \\
\text { ganador }>\text { ganadoriñ } \underline{n} \text { a } \\
\text { rapaz }>\text { rapaciño }\end{array}$ \\
\hline & & ADX. & $\begin{array}{l}\text { azul }>\text { azuliño } \\
\text { montés }>\text { montesiño } \\
\text { abafador }>\text { abafadoriñono } \\
\text { andaluz }>\text { andaluciñ }\end{array}$ \\
\hline
\end{tabular}

2.1.9. No grupo nove incluímos todos os substantivos e adxectivos rematados en $-n$, incluídos aqueles pares masculino/feminino en que a forma feminina perde a nasal (irmán/irmá, león/leoa, catalán/catalá). Cando o lema acaba en - $n$ ninguén parece dubidar de que o alomorfo empregado para a formación do diminutivo debe ser $\mid$ ciñ $\mid$ : can > canciño, man > manciña. É tamén xeral a extensión do uso deste alomorfo ás formas femininas rematadas en -á nas que historicamente houbo unha nasal (Álvarez/Xove 2002: 408), xa sexan palabras cun oposto masculino en -án (irmán/irmá > irmanciño/irmanciña) ou sen oposto masculino ningún (mazá > mazanciña). Os pares en -án/-ana, terminación reservada desde a reforma normativa de xullo do 2003 para adxectivos e substantivos que atribúen características pexorativas ou aumentativas, tamén presentan a variante $\mid$ ciñ $\mid$ tanto na forma masculina como na feminina: folgazán/folgazana > folgazanciño/folgazanciña, lambón/lambona > lambonciño/lambonciña (Álvarez/Xove 2002: 408 e Álvarez 2002: 97-98).

Son máis problemáticas as formas en -án/-á que antes da reforma normativa do 2003 eran -án/-ana, do tipo catalán/catalá (antes catalán/catalana) ou sultán/sultá (antes sultán/sultana). Estas formas engadían o alomorfo $\mid$ ciñ $\mid$ á forma masculina (catalanciño, sultanciño), de acordo co comportamento do morfema diminutivo tras nasal, e o alomorfo |iñ á forma feminina (catalaniña, sultaniña), en consonancia co resto das palabras rematadas en vogal átona (Álvarez/Xove 2002: 408 e Álvarez 2002: 97-98). Á vista dos cambios aprobados con esta reforma, semella máis lóxico e coherente tentar acomodar todos estes pares a un mesmo modelo (o dos pares en -án/-á, que é ao que agora pertencen estas palabras), nun intento de atribuír unha certa lóxica ás leis de formación do diminutivo.

Presentan tamén problemas, debido á súa falta de definición na lingua estándar, as formas en -ón/-oa, como león/leoa ou beirón/beiroa. Hai datos recompilados na lingua oral que avalan a existencia de tres posibles formas diminutivas en feminino: leoina/leonciña/leoniña, beiroina/beironciña/bei- 
roniña (Álvarez 2002: 98). Á espera dun pronunciamento normativo que aclare algo máis ao respecto, nós decidimos incluír no noso proxecto a forma que recupera a consoante nasal (leonciña, beironcina), mantendo a coherencia co resto dos pares incluídos neste grupo.

\begin{tabular}{|c|c|c|c|}
\hline TERMINACIÓN LEMA & TERMINACIÓN DIMINUTIVO & & EXEMPLOS \\
\hline$-n$ & -ciñ- & SUBST. & $\begin{array}{l}\text { can }>\text { canciño } \\
\text { man }>\text { manciña } \\
\text { irmán, irmá > irmanciño, } \\
\text { irmanciña } \\
\text { folgazán, folgazana > } \\
\text { folgazanciño, folgazanciña } \\
\text { lambón, lambona > lambonciño, } \\
\text { lambonciña } \\
\text { catalán, catalá > catalanciño, } \\
\text { catalanciña } \\
\text { león, leoa > leonciño, leonciña }\end{array}$ \\
\hline
\end{tabular}

2.1.10. O grupo dez recolle os substantivos e adxectivos rematados en $-a o$, con ou sen o correspondente feminino en $-a ́$. O diminutivo da forma feminina, cando a hai, presenta os mesmos problemas que o feminino dos pares en -án/-á aos que nos acabamos de referir no parágrafo anterior. O masculino, no entanto, presenta a dificultade de que a lingua oral non sempre representa a pronuncia do hiato gráfico final como tal hiato, senón que o transforma adoito nun ditongo (Álvarez 2002: 97). Dependendo desa pronuncia final da palabra podémonos atopar con formas diminutivas como araoiño, araiño ou araociño. Non contamos con datos suficientes sobre a lingua escrita que nos permitan decantarnos por ningunha destas formas como preferente, de maneira que polo momento mantemos as tres en pé de igualdade.

\begin{tabular}{|c|c|c|c|}
\hline \multirow{3}{*}{$\begin{array}{l}\text { TERMINACIÓN LEMA } \\
\text { masc. }-a o, \text { fem. }-a ́ a\end{array}$} & \multirow{2}{*}{$\begin{array}{l}\text { TERMINACIÓN DIMINUTIVO } \\
\begin{array}{l}\text {-íñ- } \\
\text {-ciñ- }\end{array}\end{array}$} & \multicolumn{2}{|r|}{ EXEMPLOS } \\
\hline & & SUBST. & $\begin{array}{l}\text { arao }>\text { araoiño } / \text { araiño } / \\
\operatorname{araociño}\end{array}$ \\
\hline & & ADX. & 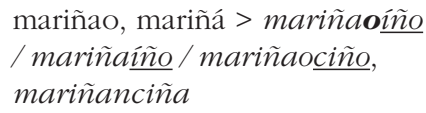 \\
\hline
\end{tabular}

2.1.11. No grupo once incluímos toda unha serie de estranxeirismos rematados en -ng. Ao noso entender, o /g/ final desta secuencia é puramente gráfico. Representa un proceso de adaptación da palabra estranxeira aínda en curso, o que se reflicte no uso de secuencias gráficas foráneas. Esta en concreto representa na lingua orixinal un son nasal, o que nos fai pensar que o diminutivo de calquera destas palabras debería comportarse como o fai tras calquera outra palabra rematada en nasal e empregar a variante $\mid$ ciñ $\mid$, tal e como se mostra no seguinte cadro. 
TERMINACIÓN LEMA TERMINACIÓN DIMINUTIVO $-n g$ (estranxeirismos) -ciñ-
EXEMPLOS

SUBST. antidoping $>$ antidopingciño big-bang $>$ big-bangciño búmerang $>$ bumerang $\underline{\text { ciño }}$

2.1.12. De maneira similar ao grupo anterior, os substantivos rematados en $-m$, a maioría deles cultismos, deberían por lóxica engadir o alomorfo | ciñ | para formar o diminutivo.

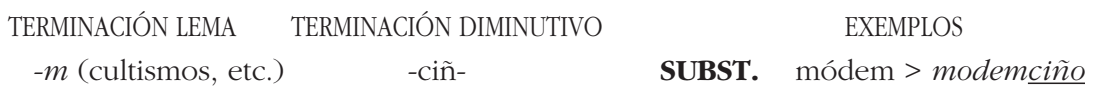

2.1.13. Os estranxeirismos rematados en $-y$, dado que este representa un son vocálico, piden de xeito natural un diminutivo en $\mid$ iñ $\mid$ con redución do $/ y^{\prime} i /$ en $/$ ii/.

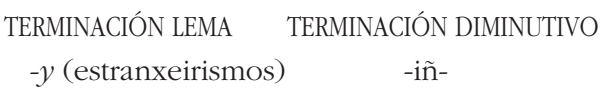

\section{EXEMPLOS}

SUBST. hippy $>$ hippiño whisky $>$ whiskiño

2.1.14. Outro dos grupos que consideramos no noso estudo inclúe toda unha serie de palabras rematadas en grupos consonánticos estraños á ortografía galega. A maioría deles son estranxeirismos e, ás veces, polo proceso de adaptación ao que nos referiamos máis arriba, mesmo os lexicógrafos mostran discrepancias á hora de escolleren a grafía máis axeitada. En consonancia coas propostas feitas para os tres grupos anteriores, semella razoable aplicar as regras máis básicas de formación do diminutivo en galego e tentar respectar ao máximo a grafía do lema segundo nos veña dada en cada caso.

$\begin{array}{lc}\text { TERMINACIÓN LEMA } & \text { TERMINACIÓN DIMINUTIVO } \\ \text {-grupos } & \text {-iñ- } \\ \text { consonánticos } & \\ \text { estraños á } & \\ \text { ortografía galega } & \\ \text { (estranxeirismos) } & \end{array}$

EXEMPLOS

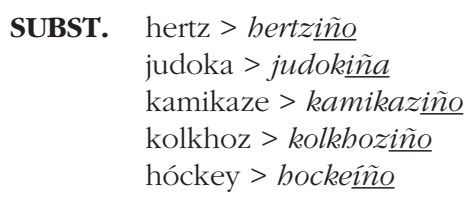

SUBST. hertz $>$ hertziño judoka $>$ judokiña kamikaze > kamikaziño kolkhoz $>$ kolkhoziño hóckey > bockeiño

2.1.15. O último grupo que presentamos recolle exemplos de substantivos rematados en $-s$ aos que resulta verdadeiramente complicado outorgar un diminutivo. En primeiro lugar, porque resulta difícil imaxinar estas formas empregadas en diminutivo. En segundo lugar, porque aínda imaxinándoas (algo que nós debiamos facer para o deseño das nosas ferramentas informáticas de revisión lingüística), calquera falante tería dúbidas sobre onde inserir o sufixo $\mid$ iñ $\mid$. A nosa proposta é engadilo ao lema, procedemento habitual nas palabras rematadas en consoante distinta de $/ \mathrm{n} /$, en todos aqueles casos 
en que queda claro que o -s final non é nin refire a un morfema de plural, senón que forma parte do tema (luns, galimatías). Naqueles casos en que o -s final nos poida facer pensar nun plural (talvez porque temos a referencia desa palabra noutras formacións), optamos por inserir o morfo |iñ | entre a raíz e os morfemas de xénero e número, como é habitual na formación do diminutivo en galego. Así, mesías pódenos remitir a mesianismo, e microcosmos a toda a familia de palabras formada sobre cosmo-, o que nos leva a propoñer os diminutivos mesiiñas e microcosmiños.

Finalmente, recollemos un par de exemplos nos que nos resulta totalmente imposible decantarnos por unha ou outra opción, de maneira que preferimos optar porque o sistema ofreza as dúas posibilidades: unha conforme á regra (pancreasiño, menosiño) e outra por analoxía (pancreiñas, meniños).

TERMINACIÓN LEMA TERMINACIÓN DIMINUTIVO
$-s \quad$-iñ-
(casos problemáticos)

\author{
EXEMPLOS \\ SUBST. luns $>$ lunsiño \\ galimatías > galimatiasiño \\ mesías > mesiiñas \\ microcosmos $>$ microcosmiños \\ páncreas > pancreasiño / \\ pancreinas \\ menos > menosiño / meniños
}

\title{
3. CONCLUSIÓNS
}

Nas páxinas anteriores tentamos sintetizar os principais grupos de substantivos e adxectivos que podemos atopar en galego e as características que cada un deles presenta á hora de formar o diminutivo.

Tras a análise realizada podemos concluír que o diminutivo, a pesar de ser unha forma usada con gran frecuencia e en multitude de contextos en lingua galega, segue sendo un campo con moito por explorar, polo menos no que respecta á súa morfoloxía. Son múltiples e variados os usos espontáneos que os falantes fan desta forma, mais apenas hai estudos que analicen todos eses usos e avalen a escolla dunha forma ou outra como estándar en cada caso concreto. Fóra duns poucos casos que están claramente definidos e para os que non semella haber discrepancia ningunha entre os falantes, a maioría dos exemplos mostran que existen marcadas diferenzas de carácter dialectal. Contamos con poucos datos de estudos que demostren a existencia e o grao destas diferenzas. Pero aínda peor, apenas contamos con información prescritiva na materia que nos permita establecer unha ou outra forma como prioritaria ou "estándar" de cara ao ensino da lingua galega ou ao desenvolvemento de ferramentas lingüísticas do tipo da nosa. 
O caso dos substantivos e adxectivos rematados en -uo/-ua ou en -üe, ou o dos pares masculino/feminino en -án/-á que antes da reforma do 2003 eran -án/-ana son dous claros exemplos desta falta de estudo e documentación a que nos referimos. O mesmo se pode aplicar a todos os grupos de estranxeirismos referidos (os rematados en $-n g$, en $-m$, en $-y$ ou en calquera outro grupo consonántico estraño á ortografía galega), aos que non atopamos ningún tipo de referencia na bibliografía consultada. Finalmente, o último grupo incluído na nosa análise pretende ser unha breve mostra da existencia (feito que se pode constatar en todas as linguas) dalgunhas palabras de morfoloxía pouco clara e, en consecuencia, con dificultades engadidas para a súa flexión.

Quedaría aínda por discutir o caso das palabras compostas, que non nos pareceu oportuno incluír nesta exposición no estado actual da cuestión. Aínda cómpren moitos estudos e investigacións sobre as palabras simples, de maneira que tanto os falantes coma os profesionais da lingua poidamos seguir unhas pautas claras e coherentes.

\section{REFERENCIAS BIBLIOGRÁFICAS}

Álvarez Blanco, R. (2002): "Gramática contrastiva do portugués e o galego: o diminutivo”, en L. Iglesias Rábade et alii (eds.): Studies in contrastive linguistics: proceedings of the 2nd International Contrastive Linguistics Conference (Santiago de Compostela, October, 2001). Santiago de Compostela: USC, 91-107.

Álvarez, R. e X. Xove (2002): Gramática da lingua galega. Vigo: Galaxia. 